\title{
Cocaine Self-Administration Selectively Decreases Noradrenergic Regulation of Metabotropic Glutamate Receptor-Mediated Inhibition in Dopamine Neurons
}

\author{
Carlos A. Paladini, Jennifer M. Mitchell, John T. Williams, and Gregory P. Mark \\ The Vollum Institute and Department of Behavioral Neuroscience, Oregon Health and Science University, Portland, Oregon 97201
}

\begin{abstract}
Stimulant drugs of abuse have several effects on neural activity, including altering the excitability of dopamine neurons via the noradrenergic and glutamatergic systems. Thus, an interaction between noradrenergic and glutamatergic systems may play a role in drugseeking behavior. Although many of the direct pharmacological effects of psychostimulants on dopamine neuron physiology are well established, the neurophysiological bases of drug-seeking behavior have yet to be fully elucidated. The present study measured shortterm ( $3 \mathrm{~d})$ and long-term (14 d) access to cocaine, by self-administration or passive exposure, and the regulation of metabotropic glutamate receptor (mGluR)-mediated inhibition of dopamine cells in rat midbrain slices. The results indicated that $\alpha$-adrenoreceptor modulation of the mGluR-mediated inhibition is selectively reduced in animals that self-administered cocaine for $3 \mathrm{~d}$. This effect was not observed in slices from either yoked cocaine animals, which were given cocaine in an amount and pattern equal to that used for the self-administering animals, or saline control animals. However, after $14 \mathrm{~d}$ of cocaine, $\alpha$-adrenoreceptor regulation of the mGluRmediated inhibition was equally reduced in both self-administering and yoked cocaine animals relative to saline controls. The results suggest that $\alpha$-adrenoreceptor regulation of the mGluR-mediated inhibition is an adaptive cellular mechanism involved in early cocaine self-administration that is distinct from a direct pharmacological effect of cocaine on dopamine neurons. The noradrenergic system could therefore serve to alter the reward value of stimuli that have significant effects on dopamine neuron firing pattern through mGluRs.
\end{abstract}

Key words: addiction; psychostimulant; self-administration; glutamate; norepinephrine; electrophysiology; ventral tegmental area

\section{Introduction}

Phasic changes in extracellular dopamine (DA) are dependent on afferents that drive the firing pattern of DA neurons. Such changes in DA concentration are critical in the processing of natural rewards (Hollerman and Schultz, 1998) and can induce drug-seeking behavior (Phillips et al., 2003). During drug abuse, direct pharmacological effects of psychostimulants override the physiological regulation of DA neuron firing, resulting in altered levels of DA in target loci. Thus, the addictive potential of psychostimulants (and other drugs of abuse) may lie in their ability to usurp the natural reward pathways (Gonon, 1988; SuaudChagny et al., 1992; Pan et al., 1996; Wise, 1996; Darracq et al., 1998; Jones and Mobley, 2000; Shi et al., 2000). However, addiction extends beyond the direct pharmacological effects of psychostimulants.

In humans, compulsive drug seeking and habitual drug use are among several criteria that indicate drug dependence and

Received March 23, 2004; revised April 20, 2004; accepted April 24, 2004.

This work was supported by National Institutes of Health Grants DA14639 (G.P.M.), DA04523 (J.T.W.), DA14735 (J.M.M.), and DA016262, and by the National Alliance for Research on Schizophrenia and Depression (C.A.P.). We thank Drs. John Crabbe and Salma Quraishi for comments on this manuscript and work and Sarah Mader for expert technical assistance.

All correspondence should be addressed to Carlos A. Paladini, Oregon Health and Science University, 3181 Southwest Sam Jackson Park Road, Portland, OR 97201. E-mail: paladini@ohsu.edu.

DOI:10.1523/JNEUROSCI.1079-04.2004

Copyright $\odot 2004$ Society for Neuroscience $\quad$ 0270-6474/04/245209-07\$15.00/0 addiction. Assuming that the psychobehavioral pathology of addiction has neurological underpinnings, researchers have developed several animal models to study the neural basis of the disease (for review, see Koob et al., 1998; McLellan et al., 2000). One of the most widely used methods is drug self-administration, whereby animals acquire small amounts of drug contingent on their behavior. To separate the pharmacological effects of drug from motivational effects, a yoked paradigm is used in which self-administering animals are paired with counterparts that receive equal amounts of drug in a response-independent manner. This method has facilitated our understanding of the effects of psychostimulants on key neurochemical pathways such as the DA system, but many of the intracellular mechanisms that may be differentially affected by passive administration versus selfadministration of psychostimulants remain poorly understood.

Burst firing in mesencephalic DA neurons is dependent on excitatory afferents that activate ionotropic glutamatergic receptors on DA cells (Darracq et al., 1998; Kitai et al., 1999; Jones and Mobley, 2000). The pause after a burst can also be mediated by glutamate acting on metabotropic glutamatergic receptors (mGluRs), which induces an IPSP (Fiorillo and Williams, 1998; Marino et al., 2001). Psychostimulants selectively reduce the mGluR-induced IPSP in DA neurons through crossdesensitization that is mediated by $\alpha$-adrenoceptors (Paladini et al., 2001). As a result, acute exposure to psychostimulant increases DA neuron bursting via $\alpha$-adrenoceptors (Shi et al., 
2000). This suggests that $\alpha$-adrenergic receptors play an important role in mediating drug reinforcement. Indeed, mice lacking $\alpha$-adrenoceptors exhibit neither psychostimulant-induced locomotor hyperactivity (Drouin et al., 2002a) nor rewarding effects (Drouin et al., 2002b). Therefore, an interaction between noradrenergic and glutamatergic systems may modulate the firing pattern of DA neurons, which in turn may underlie the reinforcing value of drugs and the establishment of addictive behavior (Bonci et al., 2003).

This study was designed to determine whether the interactive effect of glutamatergic and noradrenergic inputs on DA cell firing differed in animals that self-administered cocaine compared with yoked cocaine and saline control animals that received the same amount of cocaine or saline in a response-independent manner. We found that the sensitivity of an mGluR-mediated outward current to $\alpha_{1}$-adrenoceptor activation in DA neurons was reduced in animals that self-administered cocaine. This effect was not observed in animals that received cocaine passively or received saline. The results suggest that the reduced sensitivity to $\alpha_{1}$-adrenoceptors may be an adaptive response to cocaine self-administration.

\section{Materials and Methods}

Animals and surgical procedures. Male Sprague Dawley rats (Charles River Laboratories, Wilmington, MA), weighing $275 \mathrm{gm}$ at the beginning of behavioral testing, were housed three per cage during food training and were individually housed after surgery. The animal colony was kept at a constant temperature and followed a standard $12 \mathrm{hr}$ light/dark cycle with food and water available ad libitum. Animals were tested at the same time during their light cycle each day. All experimental protocols were approved by the Institutional Animal Care and Use Committee and were conducted in accordance with the National Institutes of Health Guide for the Care and Use of Laboratory Animals. Before cocaine selfadministration, animals were anesthetized with a ketamine-xylazineacepromazine mixture and implanted with a chronic jugular catheter using methods described previously (Grubb et al., 2002). In brief, catheters were constructed by connecting micro-renethane tubing (inner diameter, 0.012 inches; outer diameter, 0.025 inches) to a 26 gauge, L-shaped stainless-steel cannula imbedded in a threaded Teflon base (Plastics One, Roanoke, VA) and were secured to polypropylene mesh (Small Parts, Miami Lakes, FL) with cranioplastic cement. The cannula and threaded base were passed through a small hole in the skin and served as the attachment point for an infusion line to deliver cocaine. After surgery, rats were allowed to recover for 1 week, and catheters were flushed daily with $0.2 \mathrm{cc}$ of a heparinized saline solution (350 U of heparin/cc) containing the antibiotic Timentin (100 mg of ticarcillin/cc; SmithKline Beecham, Upper Merion, PA).

Food and cocaine self-administration. Animals were first trained to perform an operant response for food delivery and then allowed access to cocaine for self-administration. Training was conducted in operantconditioning chambers enclosed within sound-attenuating cabinets (Med Associates, St. Albans, VT). Each chamber contained an active and inactive lever as well as a food dispenser and two stimulus lights. Rats were trained to discriminate the active from the inactive lever. Presses on the active lever resulted in delivery of $45 \mathrm{mg}$ food pellets (Dustless precision pellets; Bioserv, Frenchtown, NJ) as a behavior reinforcer on a fixed ratio schedule of reinforcement. [Fixed ratio schedule 1 (FR1) indicates one lever press and one food pellet delivered.] Presses on the inactive lever were recorded but were without consequence. A 1 sec timeout (TO) was imposed after each response on the active lever. During the TO, the stimulus light above the active lever was illuminated and the levers were retracted. Over the course of $\sim 1$ week, the TO was gradually increased to $20 \mathrm{sec}$. Animals had ad libitum access to food at all times during training.

When stable responding for food was achieved, animals were implanted with intrajugular catheters as described above. Through these catheters, rats received (1) cocaine by self-administration, (2) cocaine in a yoked manner (see below), or (3) saline. Animals in the self- administering group were allowed to self-administer cocaine during daily $3 \mathrm{hr}$ sessions, whereas the two other groups served as yoked cocaine and saline controls. During drug-access sessions, only rats in the selfadministering group had access to levers in their cages. For these animals, presses on the active lever (FR5 for $3 \mathrm{~d}$ or FR1 for $14 \mathrm{~d}$; see below) resulted in a $120 \mu \mathrm{l}$ infusion of cocaine $\left(0.75 \mathrm{mg} \cdot \mathrm{kg}^{-1} \cdot\right.$ infusion $\left.^{-1}\right)$ over a period of $4 \mathrm{sec}$ followed by a $20 \mathrm{sec} \mathrm{TO}$, which was signaled by illumination of the stimulus light above the active lever.

Each cocaine self-administering animal was paired with (i.e., yoked to) a rat that received cocaine $\left(0.75 \mathrm{mg} \cdot \mathrm{kg}^{-1} \cdot\right.$ infusion $\left.^{-1}\right)$ for each response emitted by the self-administering rat. In this way, yoked cocaine animals received equal amounts of cocaine over the same time course as rats in the self-administering group, but their exposure to cocaine was not explicitly associated with a behavioral requirement. Saline control animals received the same volume of saline ( $120 \mu \mathrm{l} /$ infusion $)$ over a $3 \mathrm{hr}$ period. Both levers were always retracted for yoked cocaine and saline control animals. Animals in the self-administering and yoked cocaine groups were paired on the basis of their performance on lever-pressing for food to compensate for possible differences in learning. No priming infusions were given at any time.

Two cocaine self-administration experiments were performed. In the first experiment, 42 rats had cocaine exposure (by self-administration or yoking) for $3 \mathrm{~d}$ before recordings were made. Twelve additional rats received saline for $3 \mathrm{~d}$. In the second experiment, 18 rats had access to (or received yoked) cocaine for 14 consecutive days. Five additional animals received intravenous injections of saline for 14 consecutive days. In both experiments ( 3 and $14 \mathrm{~d}$ ), the number of saline infusions was determined by the mean number of cocaine infusions taken by selfadministering rats in the $3 \mathrm{hr}$ daily sessions.

Slice preparation and recordings. After behavioral testing, a maximum of two cell recordings were made per animal, with the experimenter blind to the behavioral results. Animals were typically 1 month older than when behavioral testing began and weighed $\sim 330 \mathrm{gm}$ on the day of recording. Horizontal midbrain slices $(200-220 \mu \mathrm{m})$ were submerged in a chamber $(0.5 \mathrm{ml})$ and superfused with physiological saline $(1.5 \mathrm{ml} / \mathrm{min}$, $35^{\circ} \mathrm{C}$ ). The solution was equilibrated with $95 \% \mathrm{O}_{2}$ and $5 \% \mathrm{CO}_{2}, \mathrm{pH} 7.4$, and contained (in $\mathrm{mm}$ ): $126 \mathrm{NaCl}, 2.5 \mathrm{KCl}, 1.2 \mathrm{MgCl}_{2}, 2.4 \mathrm{CaCl}_{2}, 1.4$ $\mathrm{NaH}_{2} \mathrm{PO}_{4}, 25 \mathrm{NaHCO}_{3}$, and $11 \mathrm{D}$-glucose. Membrane potential was held at $-50 \mathrm{mV}$ during voltage-clamp recordings. Whole-cell patch electrodes contained (in mM): $115 \mathrm{~K}$-methyl sulfate, $20 \mathrm{KCl}, 1 \mathrm{MgCl}_{2}, 0.1$ EGTA, 10 HEPES, 2 ATP, 0.3 GTP, and 10 creatine phosphate. Dopamine neurons were identified both visually and by the presence of large H-currents at hyperpolarized potentials (Johnson and North, 1992; Mercuri et al., 1995; Marino et al., 2001; Neuhoff et al., 2002). Additionally, the hyperpolarizing mGluR-mediated response is observed only in dopaminergic neurons in midbrain slices, whereas GABAergic neurons exhibit only a depolarizing mGluR-mediated response (Marino et al., 2001).

Evoked responses. Synaptic currents were evoked with bipolar tungsten stimulating electrodes with a tip separation of 300-600 $\mu \mathrm{m}$ and placed rostral to the recording site (within $1 \mathrm{~mm}$ ). A train of 5-10 stimuli (400 $\mu \mathrm{sec}$ at $0.3-0.5 \mathrm{~mA}$ ) was delivered at $66 \mathrm{~Hz}$ once every $60 \mathrm{sec}$. Iontophoretic pipettes were filled with $1 \mathrm{M} \mathrm{L}$-aspartate and placed within $10 \mu \mathrm{m}$ of the soma or proximal dendrite. Iontophoretic responses were evoked using a $-50 \mathrm{nA}$ current pulse ( $1 \mathrm{nA}$ backing current) for $50 \mathrm{msec}$ once every $60 \mathrm{sec}$. Evoked responses were measured as the peak amplitude relative to baseline holding current directly before stimulation. A mixture of antagonists was present during all experiments. This mixture included picrotoxin $\left(\mathrm{GABA}_{\mathrm{A}}\right)$, strychnine (glycine), 1,2,3,4-tetrahydro-6nitro-2,3-dioxo-benzo[f]quinoxaline (NBQX) (AMPA), (+)-5-methyl10,11-dihydro-5H-dibenzo[a,d] cyclohepten-5,10-imine maleate (MK801) (NMDA), eticlopride (D2), and [3-[1-( R)-[(3-cyclohexylmethyl) hydroxyphosphinyl]-2-(S)- hydroxy-propyl] amino]ethyl]-benzoic acid (CGP 56999a) $\left(\mathrm{GABA}_{\mathrm{B}}\right)$. The mGluR antagonist ( $S$ )- $\alpha$-methyl-4-carboxyphenylglycine (MCPG) was routinely used to identify the iontophoretic and synaptic responses as mediated by mGluR.

Drugs. Drugs in brain slices were applied to the slice by superfusion, except aspartate (see above). ATP, GTP, picrotoxin (100 $\mu \mathrm{M})$, L-aspartate, prazosin $(100 \mathrm{nM})$, phenylephrine $(0.03-10 \mu \mathrm{M})$, and strych- 
nine $(1 \mu \mathrm{M})$ were from Sigma (St. Louis, MO). S(-)-eticlopride (100$300 \mathrm{~nm})$ and MK-801 (50-100 $\mu \mathrm{M}$, pretreatment only) were from Research Biochemicals International (Natick, MA). NBQX ( $5 \mu \mathrm{M})$, MCPG (1 mM), and (S)-3,5-dihydroxyphenylglycine (DHPG) were from Tocris Cookson (St. Louis, MO). CGP 56999a (100-300 nM) was a gift from Novartis Pharmaceuticals (Basal, Switzerland). Cocaine-HCl was obtained from the National Institute on Drug Abuse.

Data analysis. The percentage change produced by a drug was calculated by measuring the mean amplitude of three to five responses after equilibrium had been reached (5-10 $\mathrm{min}$ ) relative to the mean of five responses before drug superfusion, and the calculated change was analyzed using a Wilcoxon signed-rank test for paired data. Once the differences in percentage changes were analyzed, the data were reported as means \pm SEM. Concentration-response curves were constructed and best-fit variables were compared using commercially available software [SigmaPlot (SPSS, Chicago, IL) and Prism (GraphPad Software Inc., San Diego, CA)]. Unpaired comparisons between two groups were made with a Mann-Whitney $U$ test.

\section{Results}

Three days of cocaine self-administration and regulation of mGluR-mediated current

In the first experiment, animals were trained to lever-press for food and subsequently allowed to self-administer cocaine for $3 \mathrm{~d}$ in the same behavioral context. On the third day of selfadministration, 21 animals self-administered an average \pm SEM of $14 \pm 1.5 \mathrm{mg} / \mathrm{kg}$ per $3 \mathrm{hr}$ session. Twenty-four hours after behavioral characterization, DA neurons were recorded in midbrain slices. The effect of the $\alpha_{1}$-adrenoceptor agonist phenylephrine $(10 \mu \mathrm{M})$ on the mGluR-induced outward current was measured and compared with the amount of cocaine selfadministration. The ability of phenylephrine to attenuate the mGluR response on DA cells in vitro correlated significantly with the amount of cocaine that the animal self-administered $(r=$ $0.46 ; p<0.05)$ (Fig. 1A,B).

When the same experiment was conducted in slices from yoked cocaine animals, the ability of phenylephrine to attenuate the mGluR outward current on DA cells in vitro did not correlate with the amount of cocaine these animals received in a responseindependent manner $(n=21 ; r=0.33 ; p>0.05)$ (Fig. 1C). Because yoked cocaine animals received the same amount of cocaine at the same time that their corresponding self-administering counterparts took an infusion, the correlation between cocaine selfadministration and $\alpha_{1}$-adrenoceptor regulation of DA neurons was not simply the result of the amount of cocaine self-administered.

The degree of inhibition induced by phenylephrine (0.03-10 $\mu \mathrm{M})$ was also significantly different between self-administering (maximum percentage inhibition, $29 \pm 4.8 \% ; n=20$ ) and control animals (yoked cocaine and saline controls) (Fig. 2). The maximum amount of attenuation of the mGluR-mediated outward current was greater in the yoked cocaine $(51 \pm 5.7 \%$ inhibition) and saline control groups ( $56 \pm 8.3 \% ; n=16 ; p<0.05$; self-administering vs control groups). There was no significant difference in the initial amplitude (self-administration, $124 \pm 17$ pA; yoked cocaine, $132 \pm 26 \mathrm{pA}$; saline control, $156 \pm 48 \mathrm{pA}$ ) or the time course of the outward current induced by aspartate. This same differential sensitivity to phenylephrine between tissues from cocaine self-administering animals and yoked cocaine animals was observed when synaptically evoked mGluR-mediated IPSCs were examined. Phenylephrine $(10 \mu \mathrm{M})$ decreased the mGluR IPSC by $26 \pm 10 \%$ in cocaine self-administering rats and $50 \pm 11 \%$ in yoked cocaine animals $(p<0.05 ; n=7)$. Similar results were obtained at a near maximum concentration of phenylephrine (1 $\mu \mathrm{M})$ (Fig. 3).

Prolonged activation of $\alpha_{1}$-adrenoceptors causes an inward

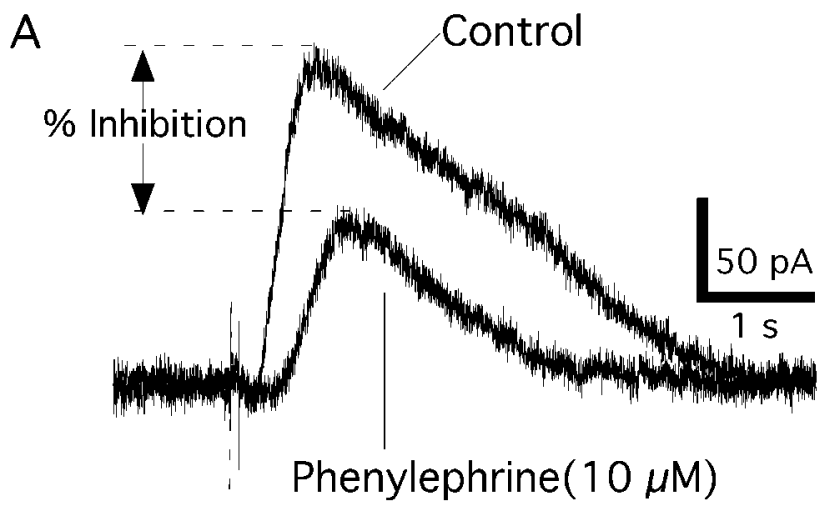

Aspartate lontophoresis

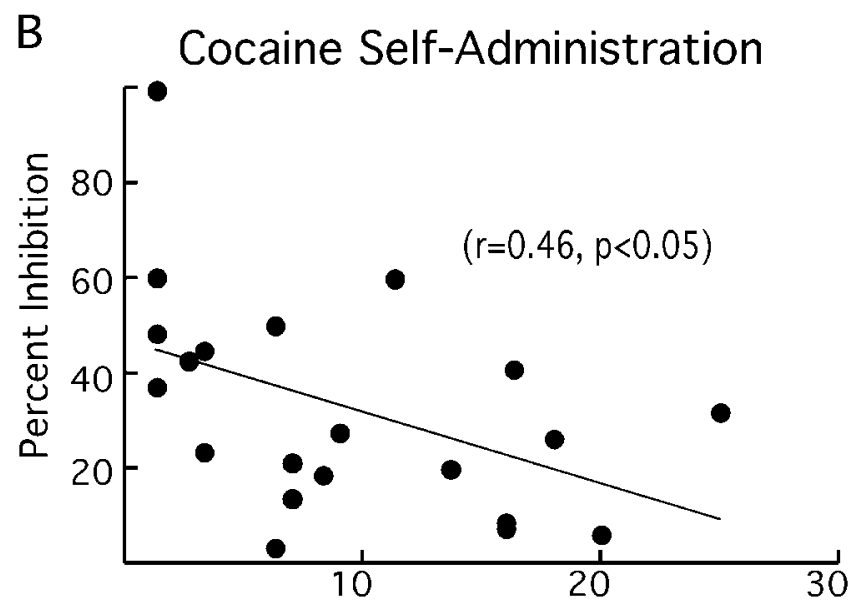

\section{Non-contingent cocaine infusions (yoked cocaine group)}

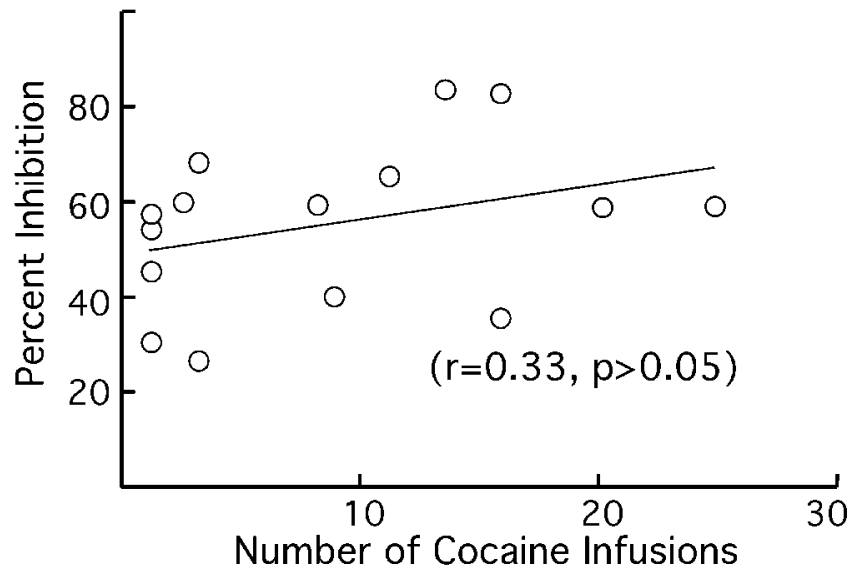

Figure 1. Attenuation of the mGluR outward current was correlated with cocaine selfadministration. A, Aspartate iontophoresis induced an mGluR-mediated outward current during whole-cell voltage-clamp recordings of a midbrain dopamine neuron taken from a rat that selfadministered cocaine. The peak amplitude of the mGluR current was decreased by bath application of the $\alpha_{1}$ agonist phenylephrine $(10 \mu \mathrm{m})$. Horizontal dashed lines indicate peak amplitude of each trace. The vertical dashed line indicates initiation of aspartate iontophoresis. $B$, The degree of attenuation of the mGluR-induced current by phenylephrine correlated significantly with the amount of cocaine that was self-administered. C, Phenylephrine-induced attenuation of the mGluR-induced current did not correlate with noncontingent cocaine infusions given to the yoked cocaine group. Diagonal solid lines in $B$ and $C$ indicate linear regression fit of data points. 
current in DA neurons (Grenhoff et al., 1995). There was no difference in the phenylephrine-induced inward holding current (self-administration inward current, $19 \pm 4 \mathrm{pA}$; yoked cocaine, $18 \pm 7 \mathrm{pA}$; saline control, $20 \pm 8 ; n=5 ; p>0.05$ ) (Fig. 4), indicating that the in vitro activation of $\alpha$-adrenoceptors was the same among cocaine self-administering, yoked cocaine, and saline control animals. The effect of phenylephrine was mediated by $\alpha$-adrenoceptors, because it was completely blocked by coapplication of the $\alpha$-adrenoceptor antagonist prazosin (100 nм; $n=4)$ (Fig. 4).

Superfusion with a low concentration of an mGluR agonist, DHPG $(1 \mu \mathrm{M})$, is known to desensitize the outward current induced by mGluR activation (Fiorillo and Williams, 1998). In the present experiment, the inhibition of the aspartateinduced outward current by DHPG was the same in slices harvested from selfadministering and yoked cocaine animals (Fig. 5). Therefore, the difference in sensitivity of the mGluR outward current to agonist desensitization is selective for agonists acting at $\alpha_{1}$-adrenoceptors.

Fourteen days of cocaine selfadministration and regulation of mGluR-mediated current

In a separate experiment, nine animals were trained to lever-press for food and subsequently tested for cocaine selfadministration for $14 \mathrm{~d}$ in the same behavioral context. Each self-administering rat was paired with a yoked cocaine animal that received the same amount of cocaine noncontingently. After $14 \mathrm{~d}$ of cocaine self-administration, the rats had reached a stable and maintained level of responding. Rats self-administered an average of $15 \pm$ $2.3 \mathrm{mg} / \mathrm{kg}$ per $3 \mathrm{hr}$ session across $14 \mathrm{~d}$. Dopamine neurons were recorded from midbrain slices $24 \mathrm{hr}$ after the last day of behavioral characterization. In slices from animals that self-administered cocaine for $14 \mathrm{~d}$, the degree of inhibition induced by phenylephrine $(10 \mu \mathrm{M})$ did not differ between self-administering and yoked cocaine animals $(p>0.05)$ (Fig. 6). However, both the self-administering and yoked cocaine groups had a blunted response to phenylephrine relative to the saline control group. Thus, recordings from yoked cocaine animals developed a blunted response similar to the selfadministering group once exposure to cocaine had lasted for $14 \mathrm{~d}$ (Fig. 6C). The reduced inhibition of the mGluR-induced current by phenylephrine is a cellular response that occurs relatively quickly in an-
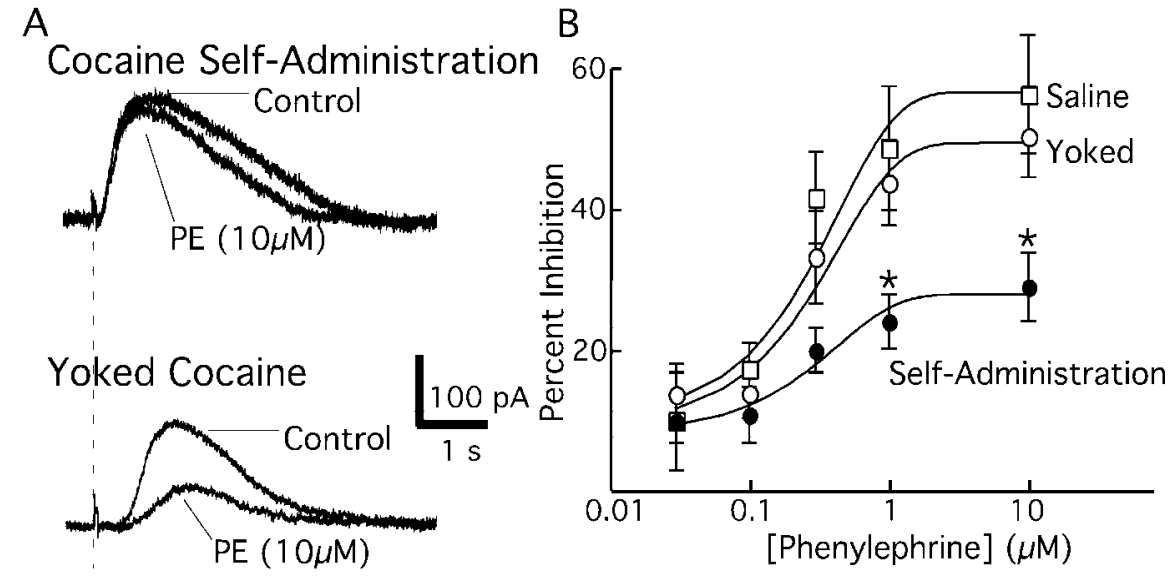

Aspartate lonto

Figure 2. Cocaine self-administration decreased the sensitivity of the mGluR outward current to $\alpha$-adrenoceptor stimulation. $A$, The degree of attenuation was less in a recording from a cocaine self-administering animal (top traces) compared with a recording taken from the corresponding yoked cocaine animal (bottom traces). The vertical dashed line indicates time of iontophoresis initiation. PE, Phenylephrine; lonto, iontophoresis. $B$, Concentration-response curves to phenylephrine constructed from slices taken from cocaine selfadministering, yoked cocaine, and saline control animals. The maximum inhibition of the outward current was diminished in the selfadministering animals, with no apparent change in $\mathrm{EC}_{50}$. Asterisks in this and subsequent figures denote significance at $p<0.05$.
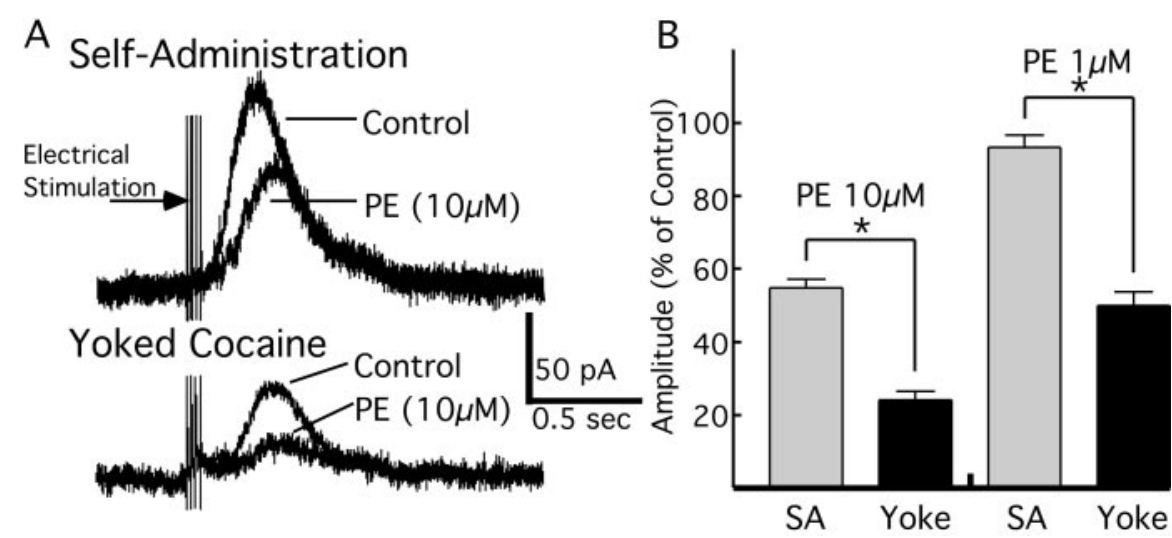

Figure 3. Phenylephrine (PE) also differentially decreased synaptically evoked mGluR IPSCs in yoked cocaine and selfadministering animals. $A$, The peak amplitude of the IPSC in a recording from a slice of a self-administering rat (top traces) was less sensitive to phenylephrine $(10 \mu \mathrm{m})$ than in a recording from a yoked cocaine animal (bottom traces). $B$, Summarized results of the effect of phenylephrine ( 1 and $10 \mu \mathrm{m}$ ) in recordings from yoked cocaine (Yoke) and cocaine self-administering (SA) animals.
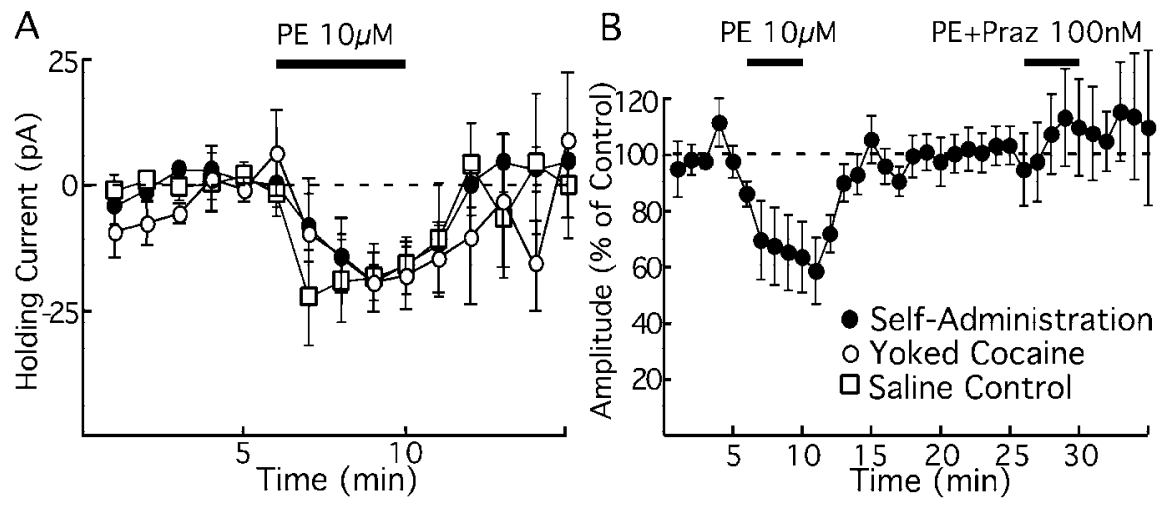

Figure 4. The difference in the regulation of the mGluR response between cocaine self-administering and yoked cocaine animals was not attributable to differences in $\alpha$-adrenoceptor activation. $A$, The effect of phenylephrine on the holding current of the recorded cell was indistinguishable among yoked cocaine, saline control, and self-administering animals. $B$, The effect of phenylephrine in slices from self-administering rats was completely blocked by coapplication of the $\alpha$-adrenoceptor antagonist prazosin. Horizontal dashed lines indicate zero current change $(A)$ and $100 \%$ of control (B). PE, Phenylephrine; Praz, prazosin. 


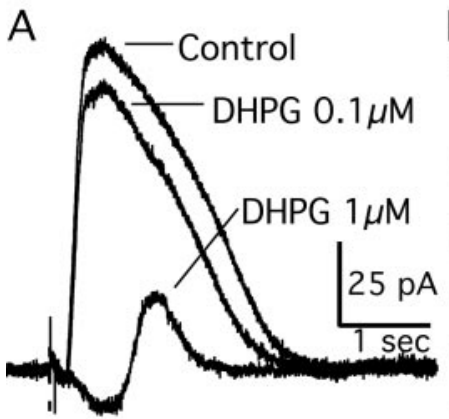

A'spartate ionto

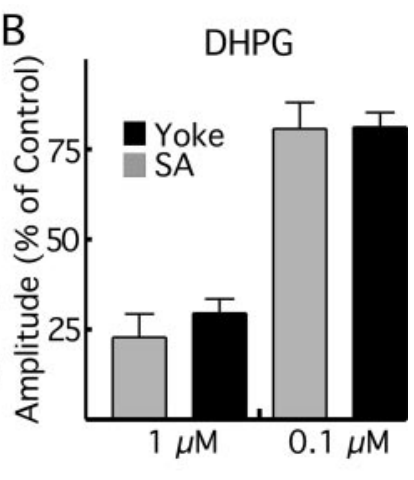

Figure 5. Regulation of the mGluR response in self-administering and yoked cocaine animals is specific to $\alpha_{1}$-adrenoceptors. DHPG decreased the amplitude of the mGluR outward current equally in yoked cocaine and self-administering animals. $A$, Traces recorded from a slice from a yoked cocaine animal showing the reduction of the peak amplitude by the mGluR agonist DHPG (0.1 and $1 \mu \mathrm{M})$. Ionto, lontophoresis. B, Summarized results of the effect of DHPG at 0.1 and $1 \mu \mathrm{m}$ between recordings from yoked cocaine (Yoke) and self-administering $(S A)$ animals.

imals that self-administer cocaine but takes longer to happen when drug is experienced noncontingently.

\section{Discussion}

Effects of cocaine self-administration on $\alpha_{1}$-adrenergic modulation of mGluR inhibition in dopamine neurons

After $3 \mathrm{~d}$ of cocaine self-administration, DA neurons had a blunted response to $\alpha_{1}$-adrenergic attenuation of the mGluRmediated outward current compared with saline controls. Passive delivery of cocaine in yoked animals was insufficient to induce this reduction, indicating that the correlation observed between the level of cocaine self-administration and the level of mGluR-mediated current attenuation was not simply attributable to differences in the amount of cocaine received. This suggests that the manner in which cocaine was experienced was an important component in determining the modulation of the mGluR outward current by phenylephrine. In addition, the difference between active and passive exposure to cocaine was selective to attenuation of the mGluR current induced by $\alpha$-adrenoceptor activation, as evidenced by the finding that the attenuation of the mGluR outward currents caused by prolonged exposure to the mGluR agonist (i.e., the desensitized response) was the same in both self-administering and yoked cocaine animals.

The differences between the mGluR current attenuation in self-administering animals and the attenuation in yoked cocaine animals after $3 \mathrm{~d}$ of cocaine experience were gone after $14 \mathrm{~d}$ of drug exposure. These findings showed that although the attenuation of the mGluR outward current in DA cells persisted from 3 to $14 \mathrm{~d}$ in cocaine self-administering animals, the difference between active and passive cocaine treatment was transient. After $14 \mathrm{~d}$ of drug exposure, DA cells in yoked cocaine animals showed a blunting of the phenylephrine-induced attenuation of mGluR current that was similar to that seen for cocaine selfadministering animals beginning on day 3 and extending to day 14. The reason for the delayed onset of the blunted phenylephrine response in the yoked cocaine group relative to the selfadministering group is not clear. The reduction in the ability of phenylephrine to modulate the mGluR-induced current may represent an adaptive response that occurs relatively quickly in animals that self-administer cocaine but takes longer to happen when drug is experienced passively.

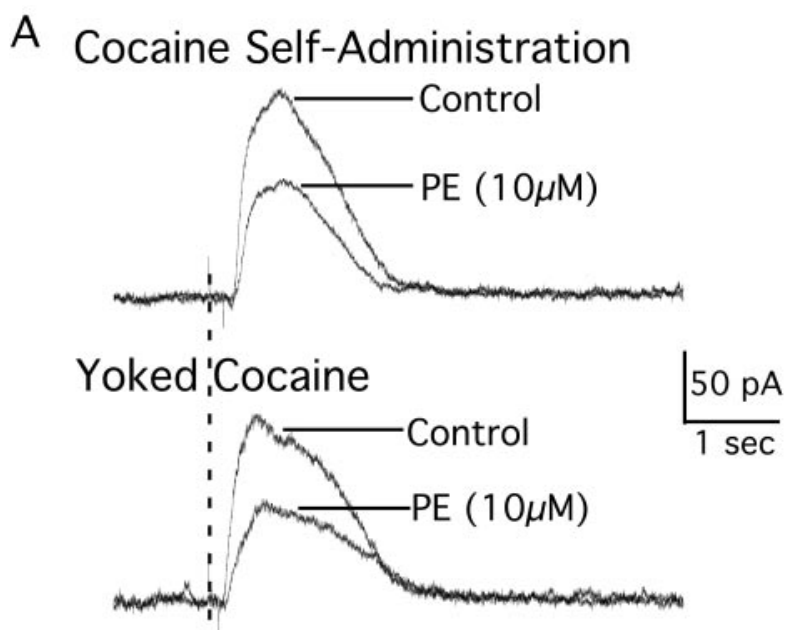

Aspartate lonto
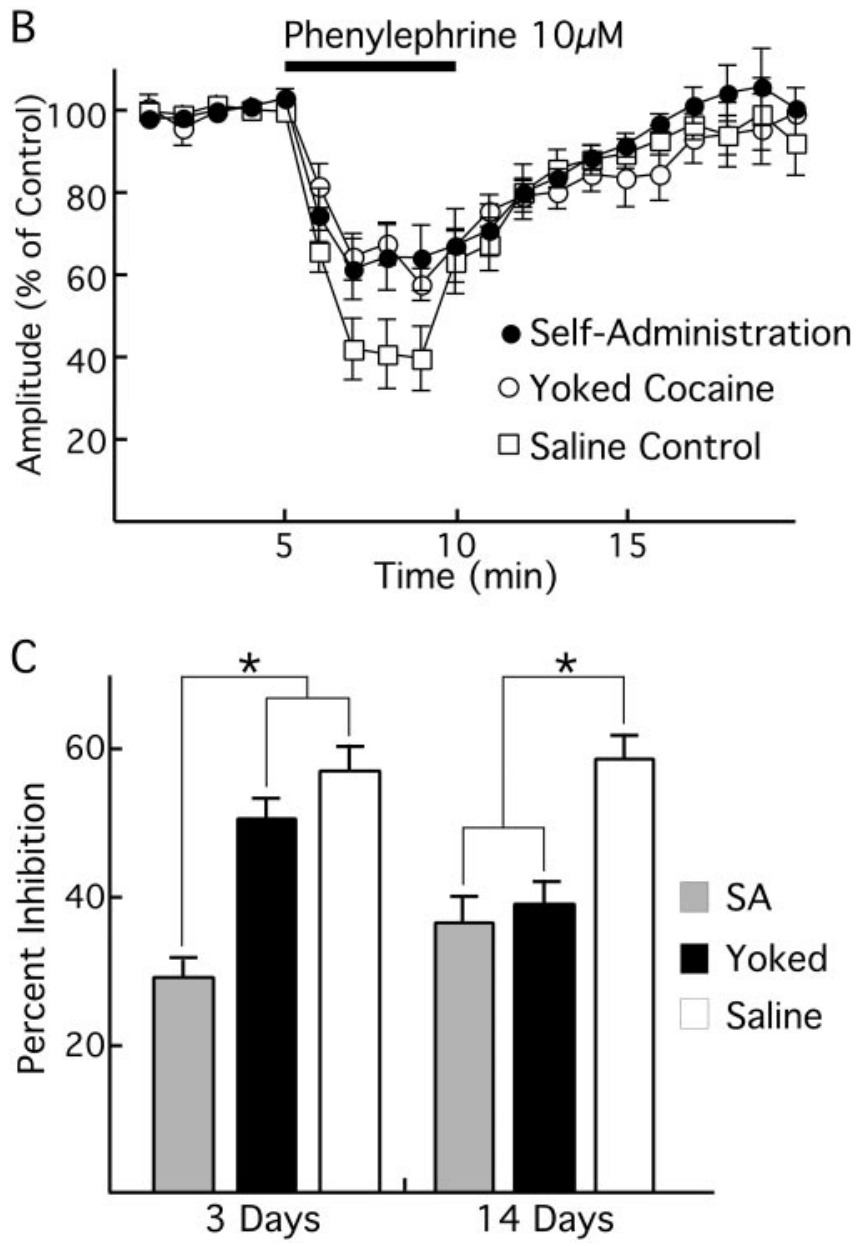

Figure 6. The decreased sensitivity, relative to yoked cocaine rats, of the mGluR outward current to $\alpha_{1}$-adrenoceptor stimulation was lost after $14 \mathrm{~d}$ of cocaine self-administration. $A$, The degree of attenuation was similar in a recording from a cocaine self-administering animal (top trace) compared with a recording taken from the corresponding yoked cocaine animal (bottom trace). The vertical dashed line indicates beginning of iontophoresis application. PE, Phenylephrine; Ionto, iontophoresis. B, Summarized results illustrating the time course of the effect of phenylephrine on the mGluR-mediated outward current amplitude in selfadministering, yoked cocaine, and saline control animals. C, Summarized data comparing the maximum effects of phenylephrine between animals taking cocaine for 3 versus $14 \mathrm{~d}$. SA, Self-administration. 


\section{Relevance of mGluR-mediated inhibitory current to DA activity and cocaine self-administration}

A reduction in the mGluR-mediated inhibitory current in response to short periods of cocaine self-administration may have an important influence on the firing patterns of DA neurons in situ. The burst-firing characteristic of DA neurons is thought to be critical for mediating terminal release of DA and hence the processing of reward signals (Schultz, 2002). Bursts cause a greater increase in extracellular DA concentration per action potential than does the single-spike, pacemaker-like activity of DA neurons (Suaud-Chagny et al., 1992); consequently, the timing and duration of bursts of DA neuron activity are critical in the control of DA release. Under normal circumstances, transient increases in DA cell firing (and consequently extracellular DA levels) are driven by the activation of excitatory ionotropic glutamatergic receptors on DA cells that promote EPSPs and initiate burst firing (Kitai et al., 1999). The EPSPs have been found to be followed by IPSPs mediated by mGluRs (Fiorillo and Williams, 1998). Thus, burst firing in DA neurons can be regulated by the combined activation of ionotropic and metabotropic receptors. The pause after a burst of action potentials, induced by the mGluR-mediated IPSP, can curtail the length of the burst and reduce the amount of DA released extracellularly in target loci. A decrease in the amplitude and duration of the IPSP would lengthen an afferent-driven burst and increase the phasic release of DA. Acute exposure to psychostimulant in vitro decreases the amplitude of the mGluR outward current in DA cells, and this effect is dependent on activation of $\alpha_{1}$-adrenoceptors (Paladini et al., 2001).

The mGluR-mediated current in DA cells from cocaine selfadministering animals was less affected by the adrenergic agonist phenylephrine but was similarly affected by desensitization by the mGluR agonist DHPG (relative to recordings from yoked cocaine animals). A low concentration of agonists that act on phosphoinositide-coupled receptors (e.g., $\alpha_{1}$-adrenoceptor, mGluR, and muscarinic ACh) decreases intracellular calcium in DA cells (Fiorillo and Williams, 2000; Paladini et al., 2001; Paladini and Williams, 2004). The different effects of phenylephrine in recordings from self-administering and yoked cocaine animals may be attributable to differences in calcium availability rather than receptor activation, because the small inward current induced by phenylephrine (bath application) was the same regardless of whether the recording was obtained from a selfadministering or yoked cocaine animal. The cellular mechanisms underlying the adrenergic regulation of the mGluR outward current have been tested directly. The outward currents elicited by $\alpha_{1}$-adrenoceptor and mGluR activation are thought to be mediated by release of calcium from separate intracellular stores, and the adrenoceptor-activated calcium pool is more sensitive to calcium-depleting agents such as ryanodine (Paladini and Williams, 2004). Thus, the selectivity for $\alpha_{1}$-adrenoceptor regulation of the mGluR-mediated current may be attributable to the difference in available calcium pools.

\section{Regulation of the mGluR outward current and drug seeking}

The reduced inhibition of the mGluR outward current by $\alpha_{1}$ adrenoceptors observed in self-administering animals suggests that burst firing in these cells would be reduced relative to controls. This was an unexpected finding, which may have several interpretations. First, a reduction in the adrenergic modulation of the mGluR-induced current may represent an intracellular adaptation to cocaine exposure that animals attempt to rectify behaviorally by increasing their intake of drug. Drug-seeking be- havior may be driven in part by a positive hedonic response induced by drugs (Koob and Le Moal, 2001; O’Brien, 2003). Repeated exposure can, under certain conditions, lead to tolerance or a progressive decline in this positive reinforcing effect. In animal models of drug seeking, this may result in increased rates of operant responding for drugs, especially early in the acquisition of the behavior (Carroll and Lac, 1997; Deroche-Gamonet et al., 2002). The blunted phenylephrine-induced effect on the mGluR current in the present study may be a cellular substrate of this behavioral response, particularly because the neurophysiological response was observed only in rats that self-administered cocaine and not in yoked cocaine rats.

A second interpretation relies on a negative reinforcement mechanism that may be a component of drug seeking (Koob et al., 1997; O'Brien, 1997). After repeated exposure, the absence of drug can lead to a state of dysphoria during withdrawal, and the ability of a drug to alleviate this dysphoria has been suggested to be a motivator for consumption (for review, see Koob and Le Moal, 2001). Reductions in DA activity or elevation of its stimulation threshold within the brain reward pathway have been associated with the negative effect of drug withdrawal (Dackis and Gold, 1985; Markou and Koob, 1992). In this study, responses were recorded $24 \mathrm{hr}$ after the last self-administration session (or yoked cocaine exposure); therefore, animals were in drug withdrawal at the time of testing. The experience of withdrawal may have contributed to the blunted phenylephrine-induced disinhibition of DA neurons. This effect was observed in the selfadministering group after $3 \mathrm{~d}$ of training and in both the selfadministering and yoked cocaine groups when drug exposure was extended to 2 weeks. These findings suggest that if withdrawal from cocaine induced a DA-deficient state, it may appear first in animals that control their drug intake. Repeated exposure to cocaine over many days may ultimately lead to a DA-deficient state regardless of the method of administration.

The present results suggest that decreased $\alpha$-adrenoceptor regulation of the mGluR-mediated current may be a cellular mechanism associated with withdrawal from, or tolerance to, psychostimulants that occurs after response-dependent but not response-independent drug administration. Indeed, previous studies have found that response-dependent administration of morphine and cocaine results in increased tolerance and withdrawal (Siegel, 1988; Dworkin et al., 1995). Additionally, studies investigating brain reward thresholds through intracranial self-stimulation also demonstrate increased tolerance after self-administration of cocaine (Kenny et al., 2003). The present results suggest that the pattern of excitatory drive associated with self-administration, in combination with changes induced by cocaine, results in an adaptive cellular response to selfadministration of cocaine that can decrease bursting in DA neurons.

\section{References}

Bonci A, Bernardi G, Grillner P, Mercuri NB (2003) The dopaminecontaining neuron: maestro or simple musician in the orchestra of addiction? Trends Pharmacol Sci 24:172-177.

Carroll ME, Lac ST (1997) Acquisition of i.v. amphetamine and cocaine self-administration in rats as a function of dose. Psychopharmacology (Berl) 129:206-214.

Dackis CA, Gold MS (1985) New concepts in cocaine addiction: the dopamine depletion hypothesis. Neurosci Biobehav Rev 9:469-477.

Darracq L, Blanc G, Glowinski J, Tassin JP (1998) Importance of the noradrenaline-dopamine coupling in the locomotor activating effects of D-amphetamine. J Neurosci 18:2729-2739.

Deroche-Gamonet V, Piat F, Le Moal M, Piazza PV (2002) Influence of cue-conditioning on acquisition, maintenance and relapse of cocaine intravenous self-administration. Eur J Neurosci 15:1363-1370.

Drouin C, Blanc G, Villegier AS, Glowinski J, Tassin JP (2002a) Critical role 
of alpha1-adrenergic receptors in acute and sensitized locomotor effects of D-amphetamine, cocaine, and GBR 12783: influence of preexposure conditions and pharmacological characteristics. Synapse 43:51-61.

Drouin C, Darracq L, Trovero F, Blanc G, Glowinski J, Cotecchia S, Tassin JP (2002b) $\alpha 1$ b-adrenergic receptors control locomotor and rewarding effects of psychostimulants and opiates. J Neurosci 22:2873-2884.

Dworkin SI, Mirkis S, Smith JE (1995) Response-dependent versus response-independent presentation of cocaine: differences in the lethal effects of the drug. Psychopharmacology (Berl) 117:262-266.

Fiorillo CD, Williams JT (1998) Glutamate mediates an inhibitory postsynaptic potential in dopamine neurons. Nature 394:78-82.

Fiorillo CD, Williams JT (2000) Cholinergic inhibition of ventral midbrain dopamine neurons. J Neurosci 20:7855-7860.

Gonon FG (1988) Nonlinear relationship between impulse flow and dopamine released by rat midbrain dopaminergic neurons as studied by in vivo electrochemistry. Neuroscience 24:19-28.

Grenhoff J, North RA, Johnson SW (1995) Alpha 1-adrenergic effects on dopamine neurons recorded intracellularly in the rat midbrain slice. Eur J Neurosci 7:1707-1713.

Grubb MC, Welch JR, Finn DA, Mark GP (2002) Cocaine self-administration alters the locomotor response to microinjection of bicuculline into the ventral tegmental area of rats. Brain Res 952:44-51.

Hollerman JR, Schultz W (1998) Dopamine neurons report an error in the temporal prediction of reward during learning. Nat Neurosci 1:304-309.

Johnson SW, North RA (1992) Two types of neurone in the rat ventral tegmental area and their synaptic inputs. J Physiol (Lond) 450:455-468.

Jones DL, Mobley CC (2000) Treatment of nicotine addiction. Tex Dent J 117:26-32.

Kenny PJ, Polis I, Koob GF, Markou A (2003) Low dose cocaine selfadministration transiently increases but high dose cocaine persistently decreases brain reward function in rats. Eur J Neurosci 17:191-195.

Kitai ST, Shepard PD, Callaway JC, Scroggs R (1999) Afferent modulation of dopamine neuron firing patterns. Curr Opin Neurobiol 9:690-697.

Koob GF, Le Moal M (2001) Drug addiction, dysregulation of reward, and allostasis. Neuropsychopharmacology 24:97-129.

Koob GF, Caine SB, Parsons L, Markou A, Weiss F (1997) Opponent process model and psychostimulant addiction. Pharmacol Biochem Behav 57:513-521.

Koob GF, Sanna PP, Bloom FE (1998) Neuroscience of addiction. Neuron 21:467-476.

Marino MJ, Wittmann M, Bradley SR, Hubert GW, Smith Y, Conn PJ (2001) Activation of group I metabotropic glutamate receptors produces a direct excitation and disinhibition of GABAergic projection neurons in the substantia nigra pars reticulata. J Neurosci 21:7001-7012.

Markou A, Koob GF (1992) Bromocriptine reverses the elevation in intracranial self-stimulation thresholds observed in a rat model of cocaine withdrawal. Neuropsychopharmacology 7:213-224.

McLellan AT, Lewis DC, O’Brien CP, Kleber HD (2000) Drug dependence, a chronic medical illness: implications for treatment, insurance, and outcomes evaluation. JAMA 284:1689-1695.

Mercuri NB, Bonci A, Calabresi P, Stefani A, Bernardi G (1995) Properties of the hyperpolarization-activated cation current Ih in rat midbrain dopaminergic neurons. Eur J Neurosci 7:462-469.

Neuhoff H, Neu A, Liss B, Roeper J (2002) $I_{\mathrm{h}}$ channels contribute to the different functional properties of identified dopaminergic subpopulations in the midbrain. J Neurosci 22:1290-1302.

O'Brien CP (1997) A range of research-based pharmacotherapies for addiction. Science 278:66-70.

O'Brien CP (2003) Research advances in the understanding and treatment of addiction. Am J Addict 12 [Suppl 2]:36-47.

Paladini CA, Williams JT (2004) Noradrenergic inhibition of midbrain dopamine neurons. J Neurosci 24:4568-4575.

Paladini CA, Fiorillo CD, Morikawa H, Williams JT (2001) Amphetamine selectively blocks inhibitory glutamate transmission in dopamine neurons. Nat Neurosci 4:275-281.

Pan WH, Sung JC, Fuh SM (1996) Locally application of amphetamine into the ventral tegmental area enhances dopamine release in the nucleus accumbens and the medial prefrontal cortex through noradrenergic neurotransmission. J Pharmacol Exp Ther 278:725-731.

Phillips PE, Stuber GD, Heien ML, Wightman RM, Carelli RM (2003) Subsecond dopamine release promotes cocaine seeking. Nature 422:614-618.

Schultz W (2002) Getting formal with dopamine and reward. Neuron 36:241-263.

Shi WX, Pun CL, Zhang XX, Jones MD, Bunney BS (2000) Dual effects of $\mathrm{D}$-amphetamine on dopamine neurons mediated by dopamine and nondopamine receptors. J Neurosci 20:3504-3511.

Siegel S (1988) State dependent learning and morphine tolerance. Behav Neurosci 102:228-232.

Suaud-Chagny MF, Chergui K, Chouvet G, Gonon F (1992) Relationship between dopamine release in the rat nucleus accumbens and the discharge activity of dopaminergic neurons during local in vivo application of amino acids in the ventral tegmental area. Neuroscience 49:63-72.

Wise RA (1996) Addictive drugs and brain stimulation reward. Annu Rev Neurosci 19:319-340. 